\title{
On the Reform and Exploration of New Energy Automobile Professional Education Based on the New Situation
}

\author{
Han Yajun \\ Jiangsu University of Technology Departments of automotive and traffic engineering, \\ Changzhou, Jiangsu, 213001, China
}

\begin{abstract}
At present, new energy vehicles have developed rapidly, not only occupy a relatively high share in the market, but also increase the demand for related talents.However, according to the analysis of the current automobile professional education system, the automobile market can not be satisfied. Therefore, the automobile professional education should be reformed, and the automobile research center should be set up for the students to have the automobile practice platform. So that new energy vehicles to achieve good development, enhance innovation.
\end{abstract}

Keywords: New Energy; Automobile Major; Education Reform

\section{Introduction}

In the new situation, the competition in the automobile industry is becoming more and more fierce, so it is necessary for talents to have comprehensive ability, so when training automobile talents, we should also combine many aspects.At the same time, the teaching system of automobile specialty is optimized so that students can use more advanced automobile equipment, which can not only study the new energy automobile system, but also strengthen the relevant skills of automobile specialty and become senior talents.

https://doi.org/10.47852/bonviewCETR2020010210

This is an open access article published by the BON VIEW PUBLISHING PTE. under the Creative Commons Attributions License. 


\section{Overview of new energy vehicles}

In the new period, the mode of economic development began to gradually transform, in which energy utilization has now become a relatively important in the transformation, and the concept of new energy vehicle has made the transformation and utilization of energy reasonable.From some aspects, new energy vehicles usually use clean energy or some newly developed energy as the main power energy of the vehicle, and its fundamental starting point is to replace gasoline and diesel oil, thus becoming the subjective power energy.For the new energy vehicle, it not only has high performance and price ratio, but also has high quality energy utilization function, which can reduce the dependence of automobile on traditional energy, and can meet some basic requirements of automobile industry in real time and relieve environmental pressure.In the stage, reform and innovation began to become the key feature of the times. According to the development of the industry, the utilization of new energy can enhance the competitiveness of the industry, and the new energy vehicles not only provide the basic needs for industrial upgrading, but also effectively respond to the national call.In the new era, the state has also brought policy support to new energy vehicles, such as fiscal policy to hold stable funds for new energy vehicles ${ }^{[1]}$.Not only can automobile R \& D have sufficient funds, but also get the corresponding experimental support, which provides a relatively stable environment for its innovation and development.In addition, the new energy vehicle belongs to the product of the times, which is not only the important result of the development of science and technology, but also the obvious characteristic of the development of the times. Only by obtaining more technical support can the new energy vehicle change from fantasy to possibility and promote the development of automobile.

\section{New Energy Vehicle Professional Training Goal}

In the new environment, in order to train the talents in the field of new energy automobile, it is necessary to strengthen the teaching of professional technology and theory in combination with the overall situation of modern automobile, so as to play a full role in the automobile design industry or automobile heat manufacturing industry.Notably, new energy vehicles cover multiple layers, such as automotive development, and include automotive design and testing. Therefore, when training talents, we should determine the goals in advance, investigate them effectively from the perspective of professional knowledge and practical ability, and at the same time measure the spirit of innovation so that they have these three abilities. And then become a senior automobile industry talent.Now the new energy vehicle has gradually become the most important development direction of the automobile industry. If students can study the performance of the automobile and participate in the overall design or manufacture of the automobile, they can not only enhance their own ability. It can also strengthen the 
professional quality of the automobile.In addition, the automobile specialty should also let the students have the relevant knowledge of automobile construction, master the automobile construction system, and be able to distinguish accurately. In the information age, the automobile specialty also meets the requirement of information teaching.

III. Effective Measures for the Reform of Professional Education of New Energy Automobile under the New Situation

\section{A. Strengthening the Reform of Theory Teaching}

For automobile students, theoretical teaching is indispensable. Only by learning the theoretical knowledge of automobile and understanding some physical principles of automobile movement can we analyze the internal implementation of automobile and enhance our professional accomplishment.The teaching of automobile theory often contains physical knowledge, such as electromechanical principle or electrical principle. Therefore, in teaching, we should add certain physics courses, deepen students' study of electromechanical and electrical principles, and improve their knowledge level. In order to master the various abilities of the car.At the same time, when making the teaching plan, we should also analyze the main teaching courses and select the main contents according to the teaching characteristics of new energy vehicles, which can not only make the teaching of automobile specialty have a clear knowledge system of backbone ${ }^{[2]}$.It can also promote students to study systematically and improve their learning effect.During this period, we should integrate information elements organically, so that the teaching of automobile theory can be enriched day by day, and new energy vehicles still belong to a relatively new major, so in teaching, we must properly integrate the relevant characteristics of the times. And today's era is dominated by big data information.Therefore, in the education of talents, we should also integrate information technology with automobile specialty teaching, make it connect and improve teaching effect. For example, the network hardware equipment can be added let students complete car drawing homework with network, at the same time, can query new teaching materials in real time, understand the latest information of new energy vehicles, and improve the teaching quality.

\section{B. Strengthening the Reform of Experimental Teaching}

Experimental teaching belongs to the key content of automobile teaching, but from the current automobile practice teaching, the scope of application is narrow, usually limited to some small levels, so that the students' automobile practice skills have not been improved ${ }^{[3]}$.Therefore, it is necessary to expand the scope of practice to ensure that students can contact the frontier or new automobile field, so that students can truly enrich themselves in automobile practice.During this period, the school should deepen the cooperation with the enterprise, increase the relevant frequency of the student practice, let 
the student obtain the good practice opportunity, achieve the goal of improving the practical ability. From the current discipline training, usually, the laboratory is regarded as the main training site, but some automobile test equipment is old and can not meet the needs of students.Therefore, when arranging the experimental class, it is necessary to expand the content and let a variety of automobile parts be added to the experiment to improve the teaching effect of automobile experiment.In this process, the teaching method of automobile project can be implemented, so that students can complete the specific automobile project and achieve the purpose of training automobile skills.From the point of view of automobile enterprise demand, it usually includes design production type and test maintenance type, in which we can take test maintenance type as an example to carry out project teaching. Let students systematically diagnose and troubleshoot automobile faults and analyze some cases in maintenance enterprises.During this period, students are required to receive customers, carefully inquire about vehicle conditions, then test and judge, and finally maintain and maintain.This can be done by groups, such as mechanical and electrical majors and inspectors, to allow students to repair all parts of the car according to their own duties, in which during the maintenance period, mechanical and electrical majors or inspectors should do a good job of self-inspection, mutual inspection, and accurate filling out of the inspection form, so to not only summarize the inspection process, but also understand the shortcomings and achieve the purpose of improvement.

C. Strengthening improvements in teaching equipment

In the teaching of new energy vehicles, we can not do without the corresponding teaching equipment. Under the influence of the characteristics of this major, some new energy vehicles should be introduced in the purchase of teaching equipment, so that students can study them and contact the latest products.First of all, students should study not only the different parts of the car, but also the automobile fuel system and the motion system. At the same time, they should analyze each system deeply[4. Achieve the purpose of deep learning. The school can introduce equipment scientifically by purchasing and cooperative $\mathrm{R} \& \mathrm{D}$, so that students can carry out research and improve practical skills.In addition, people who have a certain position in the automobile industry should be introduced as automobile test teachers. On the one hand, they have a better understanding of automobile structure, have a strong professional, on the other hand, they can deepen the whole automobile test teaching.In carrying out the experimental class, we should start from different forms, so that students can choose the learning content, so that they can not only choose the car learning content they are interested in, but also discuss with others. Seek experimental solutions.For example, discuss the mechanism or performance system of automobile, increase its understanding and improve learning effect.At the same time, when arranging 
the design experiment, we should choose a more flexible way to make the automobile students interested and enhance their comprehensive study.From the perspective of the overall development of new energy vehicles, it is relatively young, so it is crucial to improve the existing teaching equipment, automobile technology or automobile equipment. This can not only make students accept some new knowledge in real time, but also have the opportunity of systematic research or in-depth exploration to realize innovation and development.

\section{Strengthening teacher training}

After all, new energy vehicles belong to higher vocational subjects with equal emphasis on professional knowledge and skills, so teachers play an important role in education, but now new energy teaching is usually taught by traditional automobile teachers. Because traditional cars have a history of nearly 100 years, the basic curriculum is relatively perfect.But unlike new energy vehicles, on the one hand, the professional knowledge is updated relatively quickly, and teachers need to keep pace with the times and learn from them. On the other hand, new equipment or new parts are updated quickly. Teachers should understand in real time. In order to teach efficiently and improve teaching efficiency.First of all, we should strengthen the systematic training of new energy teachers, raise the training work to a certain height, improve the teaching ability of new energy teachers, and cultivate their skills training ability.For example, to build a training base for teachers to study regularly at the training base, and to carry out training work in conjunction with a simulated training bench to ensure that teachers have a full understanding of hybrid and hydrogen fuel vehicles, In order to teach students to clearly show ${ }^{[5]}$.In addition, for new energy vehicles, students of this major often work closely with electrical connections, so it is necessary for students to be able to simulate effectively on the bench to realize the scientific detection of the whole vehicle network. And the component circuit is judged to achieve efficient solution.In addition, new energy vehicles are mostly electrically driven, and some are made up of hundreds of volts, so teachers should also receive car safety education.For example, we should master the use of safety protective equipment and understand the harm of electric shock, so that students can be influenced by words and deeds in teaching, ensure the safety of teachers and students, and improve the quality of education.

\section{Conclusion}

From some aspects, the emergence of new energy vehicles on the one hand meets the overall development needs of the automobile industry, can promote its upgrading, on the other hand, it also breaks the traditional automobile resources, effectively protects the environment.In the face of 
the developing situation in the new era, it is necessary for colleges and universities to carry out the education work of new energy vehicles and deepen their reform so as to further realize the benign development of the automobile industry.

\section{References}

[1] Yi Xing, Zhang Yun, Cheng Wen. A Study on Construction of Vehicle Engineering Specialty in Private University [J].] under the Background of Professional Certification Jiangke academic Research ,2020,1503:19-22

[2] Peng Yuling. A Preliminary Study on the Training System of Professional Talents in Automobile Service Engineering [J].] under the New Situation Automotive Practical Technology ,2019,14:221-223.

[3] Wang Jianwei. A Study on the Implementation Path of Innovative Entrepreneurship Education in Secondary Vocational Schools of Guangdong Province Guangdong Technical normal University ,2019.

[4] Sun Huilai, Liang Yutian, Yang Hui, Zhao Jiajun. The construction of experimental system of automobile specialty under the background of science and education integration — Taking Qilu University of Technology (Shandong Academy of Sciences) as an example [J].].1 University education ,2020,01:64-67.

[5] Chen Hao, Zhao Xuan, Geng Limin, Liu Jingyu. J]. on the Training Mode of New Engineering Specialty in Automobile Based on Multi-disciplinary Interfusion Equipment manufacturing and education ,2019,3304:26-31.a

School-level education Reform project of Jiangsu univeristy of Technology in 2020 subject: Curriculum reform and research of New Energy Vehicle Construction and Principles based on OBE concept and Internet + Mode No : 11610912023 